\title{
Feeding chronology of six species of carcharhinid sharks in the western North Atlantic Ocean as inferred from longline capture data
}

\author{
William B. Driggers III*, Matthew D. Campbell, Eric R. Hoffmayer, \\ G. Walter Ingram Jr.
}

National Marine Fisheries Service, Southeast Fisheries Science Center, Mississippi Laboratories, Pascagoula, Mississippi 39567, USA

\begin{abstract}
Time-at-capture data for 6 species of carcharhinid sharks were collected during 2692 fishery-independent longline sets conducted in the western North Atlantic Ocean from 1995 through 2009. As operations occurred continuously throughout the diel cycle, time-at-capture data were used as a proxy for natural feeding behavior to examine the diel feeding chronology of blacknose Carcharhinus acronotus, spinner C. brevipinna, bull C. leucas, blacktip C. limbatus, sandbar C. plumbeus, and Atlantic sharpnose Rhizoprionodon terraenovae sharks. All 6 species were collected during all hours of the diel cycle; however, application of circular statistics revealed that spinner, bull, blacktip and sandbar sharks increased their feeding activity during nocturnal hours. Atlantic sharpnose and blacknose sharks exhibited no significant directedness in time-ofcapture, indicating that these 2 species lack distinct feeding patterns. The species-specific differences in feeding chronologies of the sharks examined demonstrate that broad generalizations concerning the feeding behavior of sharks are not appropriate.
\end{abstract}

KEY WORDS: Chondrichthyes $\cdot$ Elasmobranch $\cdot$ Carcharhinidae $\cdot$ Diel behavior

\section{INTRODUCTION}

Many shark species are top predators and as such play significant roles within the ecosystems they inhabit (Cortés 1999), including facilitating energy transfer among upper trophic levels (Wetherbee \& Cortés 2004) and influencing mortality rates and behavior of prey species (Heithaus 2004). Despite the ecological importance of sharks in aquatic ecosystems, aside from dietary studies, little is known about their feeding habits. Filling critical gaps in our knowledge concerning shark feeding behavior is needed to increase our understanding of shark bioenergetics, niche space partitioning and top down control of prey populations, all of which have broader implications for the appropriate management and conservation of shark species. Diel feeding chronology is one compo- nent of shark feeding behavior for which little is known.

While most tropical and temperate fishes are known to feed primarily during distinct diurnal, nocturnal or crepuscular periods (Helfman 1986), the diel feeding patterns of most shark species remain enigmatic. Beyond anecdotal accounts, much of what is known concerning diel feeding patterns of sharks is inferred from correlating time-of-capture with stomach content analyses. Cortés (1997) reviewed the use of stomach content data in elucidating feeding patterns in elasmobranchs and concluded that the sampling gear, experimental design and statistical analyses employed in a given study can individually or in toto lead to conflicting conclusions. For example, Cortés et al. (1996) studied the feeding chronology of bonnetheads Sphyrna tiburo off the coast of southwest Florida by examining the stomach contents of individuals caught 
in gill nets throughout the diel cycle. When grouping their stomach content weight data into $3 \mathrm{~h}$ intervals the authors determined feeding activity was generally highest during the day; however, when grouping data into $4 \mathrm{~h}$ intervals, peak feeding generally occurred in the afternoon and night.

Telemetry data have also been used to infer diel feeding patterns in several shark species; however, such information can also lead to ambiguous conclusions as increased movements, often assumed to be indicative of foraging, could be related to non-feeding behaviors such as movements within an individual's home range or between foraging areas (Heithaus 2004). For example, Sciarrotta \& Nelson (1977) tracked 14 blue sharks Prionace glauca in the eastern Pacific Ocean and found these sharks to be most active during nocturnal periods, as indicated by increased frequency of dives through the water column. This finding led the authors to conclude that while blue sharks feed during all hours of the day, peak feeding occurs at night; however, based on analyses of stomach contents, Kubodera et al. (2007) concluded that blue sharks in the western Pacific Ocean feed primarily during the day.

While analyses of stomach content and telemetry data have provided valuable information on the feeding chronology of sharks, an overlooked method of examining diel feeding activity is the use of baited hooks which, with the exception of foul hooking, require that a shark voluntarily approach and actively attempt to feed in order to be captured. To our knowledge, only 2 studies have investigated diel trends in catch rates, albeit briefly, of a shark species using baited gear (Medved \& Marshall 1981, Heithaus 2001). If soak times are limited in duration and gear is deployed repeatedly over $24 \mathrm{~h}$ cycles, time-ofcapture data are well-suited to investigate diel feeding patterns of predatory fishes. Furthermore, if data are collected in this manner, results can be based on statistical analyses that do not rely on binning methodologies or subjective interpretation. The objective of the present study was to utilize time-ofcapture data collected during a fishery-independent survey to examine the relationship between times-ofcapture and catch rates of carcharhinid sharks in the western North Atlantic Ocean.

\section{MATERIAL AND METHODS}

From 1995 to 2009, bottom longline sets were conducted at randomly selected sites in the western North Atlantic Ocean from approximately August through September during survey operations conducted by the National Marine Fisheries Service, Southeast Fisheries Science Center, Mississippi Laboratories. Operations, including gear deployment, gear retrieval and transiting between sampling sites, occurred continuously over each $24 \mathrm{~h}$ period with set times for each sampling location not being predetermined. Longline gear consisted of $1852 \mathrm{~m}$ of $4 \mathrm{~mm}$ diameter monofilament mainline and 100 gangions, which were constructed of a snap, $3.7 \mathrm{~m}$ of $3 \mathrm{~mm}$ diameter monofilament leader and a hook. Hook type varied with no. $3 \mathrm{~J}$-hooks (Mustad, model no. 34970D) used from 1995 through 1998 and 15/0 circle hooks (Mustad, model no. 39960D) used from 2001 to 2009; during 1999 and 2000 both hooks types were used.

Gear soak times were limited to $1 \mathrm{~h}$ and defined as the time elapsed between completion of deployment and initiation of retrieval. On a limited number of occasions, soak time exceeded $1 \mathrm{~h}$ due to factors such as adverse weather; therefore, data from sets with soak times $>75$ min were omitted from analyses $(\mathrm{n}=$ 45). The fork length (FL) of all captured sharks was measured to the nearest $\mathrm{mm}$ from the tip of the rostrum to the posterior notch of the caudal fin or was estimated by experienced personnel for those captured sharks that were observed but could not be landed. Time-of-capture for each shark was considered the local time (Eastern Daylight Savings Time or Central Daylight Savings Time) at the midpoint of the soak. It was assumed that for a shark to be captured on longline gear required that the individual actively attempted to feed on a baited hook, with the exception of foul-hooked individuals, and therefore was indicative of natural feeding behavior.

Species-specific catch data from each longline set were treated in aggregate such that 1 time-ofcapture data point was assigned to each observed species on a given set regardless of the number of individuals captured. This was done to avoid bias associated with exceptionally high catches resulting from schooling behavior or sampling within an area of increased abundance (e.g. high localized prey abundance). Catch data from 6 shark species, including blacknose Carcharhinus acronotus, blacktip $C$. limbatus, bull C. leucas, sandbar C. plumbeus, spinner $C$. brevipinna and Atlantic sharpnose Rhizoprionodon terraenovae sharks were analyzed. Additionally, analyses of catch data from a predatory teleost, great barracuda Sphyraena barracuda, were included for comparative purposes.

As time is on a circular scale, directional statistics were used to examine diel trends in times-of- 
captures. Each time-of-capture was converted to an angle and then the mean angle, length of the mean vector $(r)$, concentration $(\kappa)$, which is a measure of divergence from a uniform distribution, and mean time $(t)$ where calculated following the methodologies of Fisher (1993) and Zar (1999) on a speciesspecific basis. Both $r$ (range $=0$ to 1 ) and $\kappa$ (range $=0$ to 2 for most circular data) increase in value as data become more coincident with $t$ (Fisher 1993). Rayleigh's test was used to assess the presence or absence of statistically significant directedness in time-at-capture and gear deployment time data. As Rayleigh's test assumes data conform to the von Mises distribution, Watson's $U^{2}$-test was used to test the goodness of fit between the von Mises and observed distributions (Zar 1999). A $U^{2}$ p-value less than or equal to 0.05 would indicate that the time-atcapture data are multimodal and thus violate the assumption of Rayleigh's test. Directional statistic tests were conducted using the program Oriana (Kovach Computing Services, version 3.13).

\section{RESULTS}

During the study, 2692 longline sets were conducted (Fig. 1) with a soak time of $61.25 \pm 2.90$ min (mean \pm $\mathrm{SD})$. There was no significant directedness in set times $\left(Z=1.50, \mathrm{p}=0.22, U^{2}=0.01, \mathrm{p}>0.5\right)$, demonstrating that sampling occurred equally during all hours. Atlantic sharpnose sharks were the most commonly caught sharks and constituted the largest percentage of the catch of species of interest $(90 \%)$, followed by blacknose $(3.5 \%)$, blacktip $(2.3 \%)$, sandbar $(1.7 \%)$, spinner $(1.1 \%)$, and bull $(0.6 \%)$ sharks (Table 1$)$. With the exception of bull sharks, all life stages for each species were captured. However, in all cases, size-at-capture data were skewed toward juvenile and adult size classes (Table 1). Barracuda represented $<1 \%$ of the captures of species of interest and ranged in size from 667 to $1500 \mathrm{~mm}$ FL (Table 1).

All species examined were captured during all hours of the $24 \mathrm{~h}$ cycle. Time-at-capture data for each species conformed to the von Mises distribution (Table 2), verifying that all subsequent analyses utilizing Rayleigh's test were valid. Atlantic sharpnose and blacknose sharks, which are small-bodied species, showed no significant diel trends in $t$, whereas blacktip, bull, sandbar and spinner sharks, all of which are large-bodied species, showed significant directedness in $t$ toward nocturnal hours (Table 2, Figs. 2 \& 3). The mean times-at-capture for blacktip, bull and sandbar sharks were associated with midnight, whereas spinner sharks had a $t$ of $21: 27 \mathrm{~h}$. Of the 4 species that showed significant directedness in $t$, the $r$ and $\kappa$ values were approximately equal for blacktip, sandbar and spinner sharks. Bull sharks had the highest $r$ and $\kappa$ values of all shark species examined, demonstrating that this species has the greatest affinity for nocturnal feeding of the shark species examined. Catches of great barracudas were significantly higher during the day, with $t$ being 12:55 h (Table 2, Fig. 4). Of the 129 sets where great barracudas were captured, $91.5 \%$ of captures occurred during the diurnal period and $r$ and $\kappa$ values were approximately 2 to 5 times greater than that of any of the shark species that showed significant directedness in $t$.

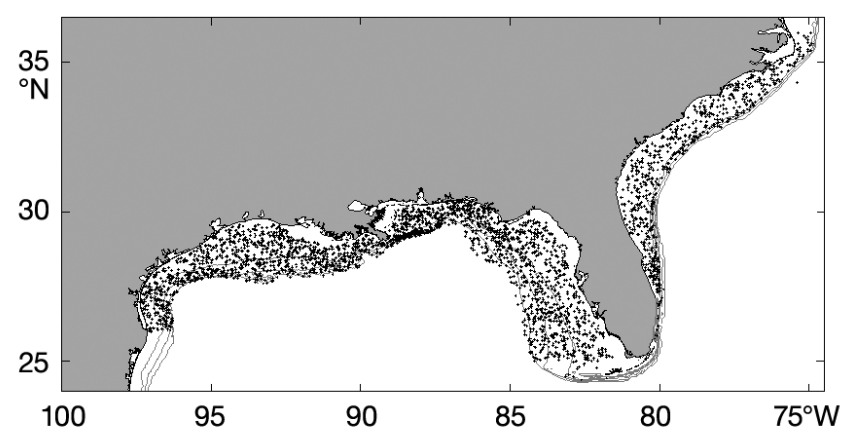

Fig. 1. Sampling locations in the western North Atlantic Ocean. Each symbol on the scatterplot along the coast represents 1 longline set $(n=2692)$. The 50, 100 and $200 \mathrm{~m}$ isobaths are indicated

Table 1. Carcharhinus acronotus, C. brevipinna, C. leucas, C. limbatus, C. plumbeus, Rhizoprionodon terraenovae and Sphyraena barracuda. Number of longline sets where at least 1 individual of indicated species was captured, total number of individuals captured, size range ( $\mathrm{mm}$ fork length) and mean size (mm fork length) for great barracuda Sphyraena barracuda and the 6 species of carcharhinid sharks examined in this study

\begin{tabular}{|lrrrc|}
\hline \multirow{2}{*}{ Species } & Sets & Individuals & \multicolumn{2}{c|}{ Size $(\mathrm{mm})$} \\
\cline { 4 - 5 } & $(\mathrm{n})$ & $(\mathrm{n})$ & Range & Mean $\pm \mathrm{SD}$ \\
\hline Atlantic sharpnose shark & 1303 & 15056 & $219-985$ & $735 \pm 98.36$ \\
Blacknose shark & 586 & 1841 & $400-1100$ & $856 \pm 123.05$ \\
Blacktip shark & 389 & 1220 & $549-1600$ & $1057 \pm 204.92$ \\
Bull shark & 104 & 175 & $997-2600$ & $1557 \pm 351.21$ \\
Sandbar shark & 292 & 466 & $545-2250$ & $1428 \pm 237.71$ \\
Spinner shark & 182 & 715 & $533-1707$ & $989 \pm 222.10$ \\
Great barracuda & 129 & 164 & $667-1500$ & $976 \pm 132.62$ \\
\hline
\end{tabular}


Table 2. Carcharhinus acronotus, C. brevipinna, C. leucas, C. limbatus, C. plumbeus, Rhizoprionodon terraenovae and Sphyraena barracuda. Circular statistics associated with mean time-of-capture $(t)$, length of the mean vector $(r)$, concentration of data ( $\kappa)$ and circular standard deviation (CSD) for great barracuda and the 6 shark species examined. Values in (): p-value of the listed test. Watson's $U^{2}$-test $\mathrm{p}$-values $>0.05$ : data conformed to the von Mises distribution

\begin{tabular}{|lcccccc|}
\hline Species & Rayleigh's $Z$ & $t(\mathrm{~h})$ & $r$ & $\kappa$ & CSD & Watson's $U^{2}$ \\
\hline Atlantic sharpnose shark & $1.59(0.21)$ & $00: 12$ & 0.03 & 0.07 & $09: 53$ & $0.02(>0.50)$ \\
Blacknose shark & $0.23(0.79)$ & $23: 22$ & 0.02 & 0.04 & $10: 41$ & $0.03(>0.25)$ \\
Blacktip shark & $6.16(<0.01)$ & $23: 14$ & 0.13 & 0.25 & $07: 46$ & $0.04(>0.25)$ \\
Bull shark & $4.90(<0.01)$ & $00: 04$ & 0.22 & 0.44 & $06: 40$ & $0.02(>0.50)$ \\
Sandbar shark & $3.23(0.04)$ & $00: 50$ & 0.10 & 0.21 & $08: 06$ & $0.03(>0.25)$ \\
Spinner shark & $3.59(0.03)$ & $21: 27$ & 0.14 & 0.28 & $07: 34$ & $0.03(>0.50)$ \\
Great barracuda & $29.57(<0.01)$ & $12: 55$ & 0.48 & 1.09 & $04: 38$ & $0.06(>0.15)$ \\
\hline
\end{tabular}

the onset of twilight. These results are consistent with anecdotal accounts of increased feeding activity of large carcharhinid sharks during the night (e.g. Springer 1943, Randall 1967) and the limited number of studies specifically addressing the feeding chronology of sharks within the genus Carcharhinus (Medved \& Marshall 1981, Medved et al. 1985, Barry et al. 2008). However, the magnitudes of $r$ and $\kappa$ as well as the multiple captures of each species throughout daylight hours demonstrate that diel trends in the

\section{DISCUSSION}

The findings of this study demonstrate that the 6 shark species examined feed throughout the diel cycle; however, our results are in opposition to the assertion of Wetherbee et al. (1990) that sharks likely do not 'exhibit measurable patterns of periodicity' in feeding activity. Catch rates of blacktip, bull and sandbar sharks showed significant nocturnal directedness in $t$ and were highest at times corresponding approximately with midnight. While $t$ for spinner sharks was $2 \mathrm{~h}$ after the latest time of sunset during our sampling, the $95 \%$ confidence interval surrounding $t$ included hours associated with dusk, suggesting this species could increase its feeding activity with feeding intensity of these sharks are not as pronounced as frequently espoused. Therefore, broad generalizations regarding the feeding ecology of sharks (e.g. Bres 1993) should be considered cautiously and, when present, statistically significant periods of increased feeding activity can be subtle and vary among species. By contrast, great barracuda time-at-capture data provide an example of a predatory fish that displays a strong diel trend in feeding intensity. This finding is supported by the reports that great barracuda are primarily diurnal feeders (e.g. de Sylva 1963, Randall 1967).

The increase in feeding intensity associated with periods of low light levels for the relatively large carcharhinids we examined suggests these predators

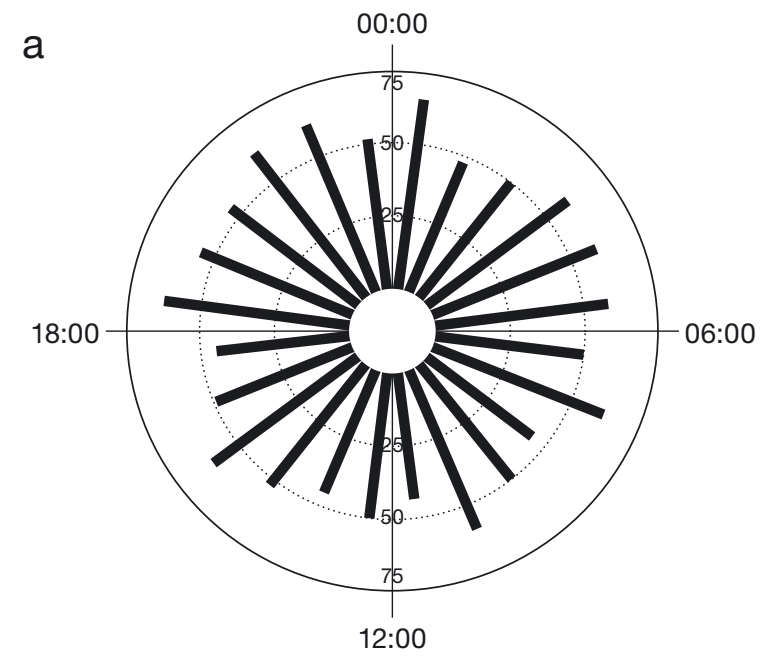

Atlantic sharpnose shark

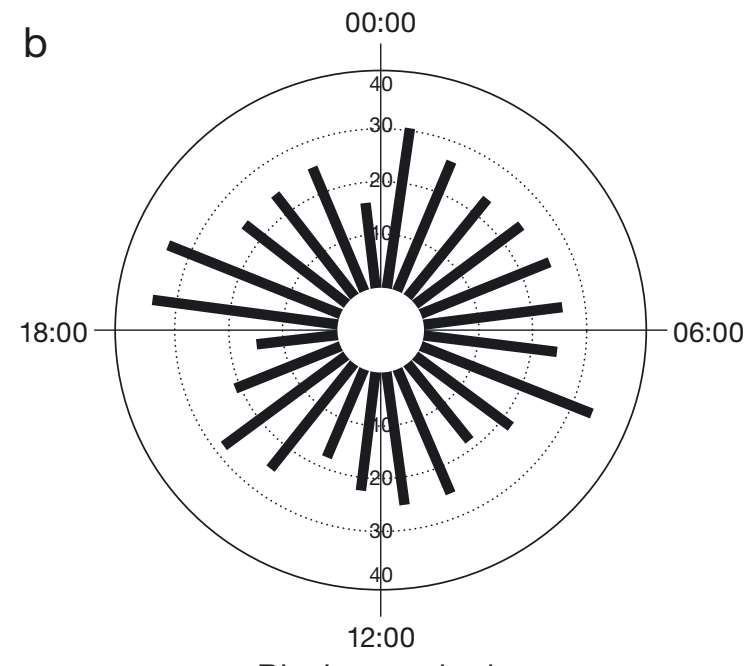

Blacknose shark

Fig. 2. Rhizoprionodon terraenovae and Carcharhinus acronotus. Time-at-capture for (a) Atlantic sharpnose sharks and (b) blacknose sharks. Outer axes represent time $(24 \mathrm{~h})$ and inner axes represent frequency of the number of longline sets where at least 1 individual was captured 


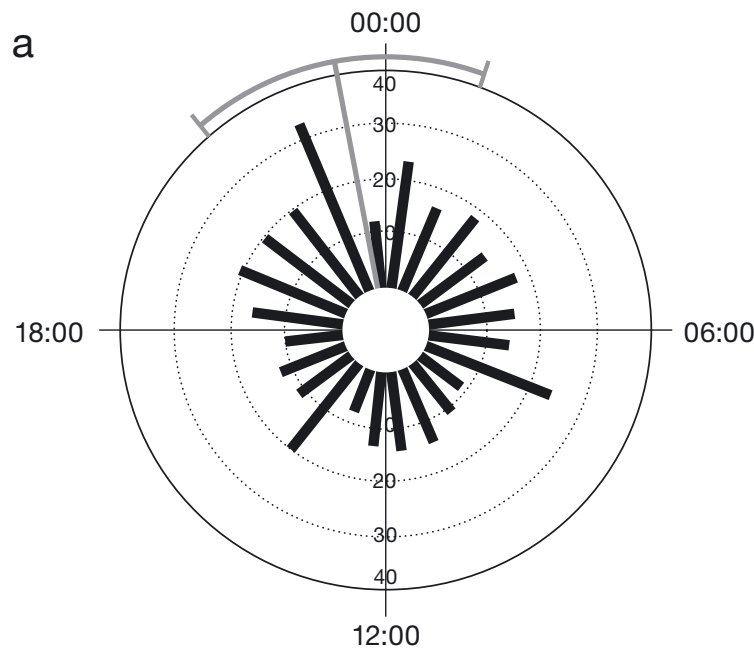

Blacktip shark

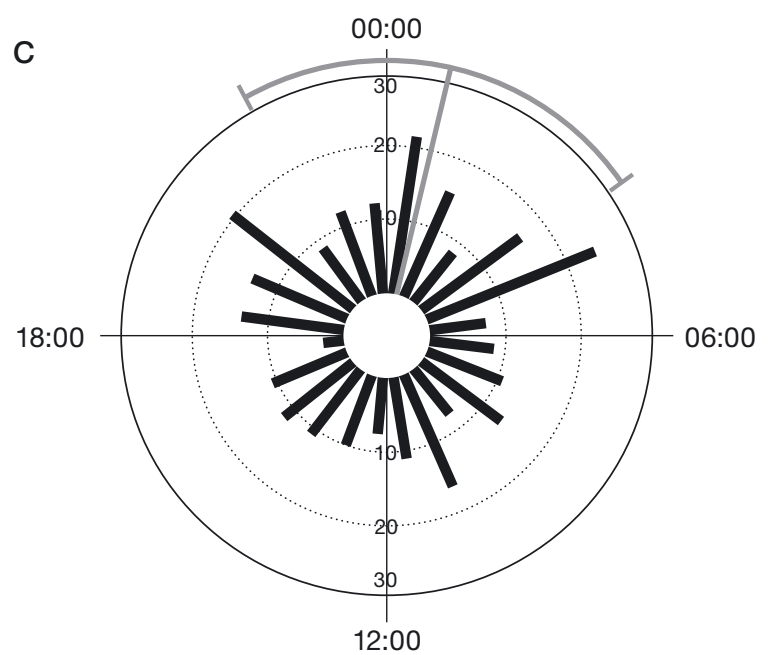

Sandbar shark

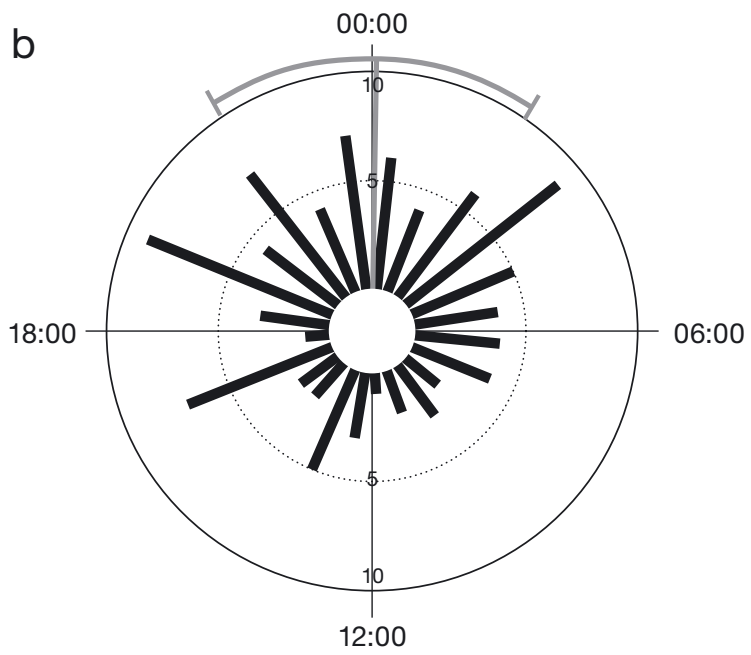

Bull shark

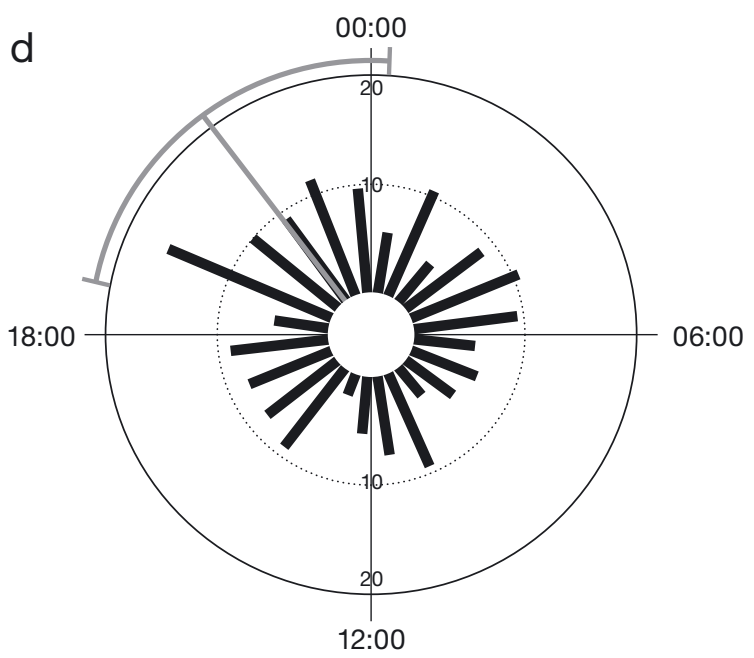

Spinner shark

Fig. 3. Carcharhinus limbatus, C. leucas, C. plumbeus and C. brevipinna. Time-at-capture for (a) blacktip sharks, (b) bull sharks, (c) sandbar sharks and (d) spinner sharks. Outer axes represent time $(24 \mathrm{~h})$ and inner axes represent frequency of the number of longline sets where at least 1 individual was captured. Vectors terminated with a $95 \%$ confidence interval represent a statistically significant mean time-of-capture

could be more physically active during nocturnal periods. If the general activity level of a given species is higher at night than during the day, then the probability of encountering potential prey (i.e. baited hook) is increased during this period. While exceptions exist (e.g. Medved \& Marshall 1983), most sharks within the family Carcharhinidae, including blue (Sciarrotta \& Nelson 1977), Caribbean reef Carcharhinus perezi (Garla et al. 2006), tiger Galeocerdo cuvier (Tricas et al. 1981), lemon Negaprion brevirostris (Gruber et al. 1988) and whitetip reef Triaenodon obesus (Whitney et al. 2007) sharks, have been shown to increase their rates of movement during nocturnal hours. Recognizing the speculative nature of interpreting increased nocturnal movements as being indicative of foraging behavior, the conclusions of these studies support our findings for 4 of the 6 species we examined. Interestingly, Medved \& Marshall (1983) reported no diel trends in activity levels for juvenile sandbar sharks. Similarly, the 2 species that did not show significant directedness in time-atcapture in our study are small-bodied, like juvenile sandbar sharks, but do not attain a large adult size.

No significant directedness in $t$ was detected in our data for Atlantic sharpnose and blacknose sharks. These results are consistent with findings of other 


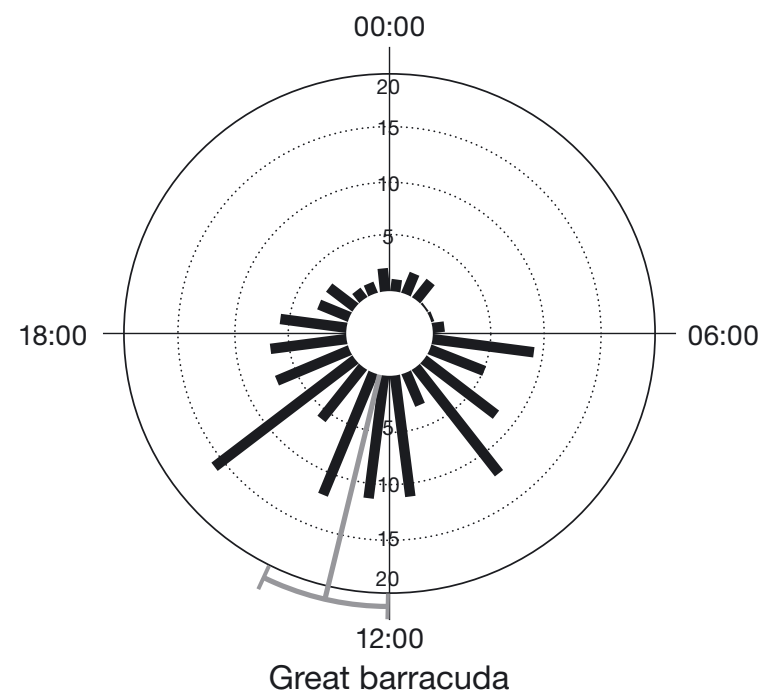

Fig. 4. Sphyraena barracuda. Time-at-capture for great barracuda. Outer axis represents time (24 h) and inner axes represent frequency of the number of longline sets where at least 1 individual was captured. Vector terminated with a $95 \%$ confidence interval represents a statistically significant mean time-of-capture

studies investigating diel changes in feeding and activity levels within the genus Rhizoprionodon. Simpfendorfer (1998) examined the diet of the Australian sharpnose shark $R$. taylori and concluded that, as the stomach contents of specimens he examined contained prey in various stages of digestion, this species feeds equally throughout the diel period. Utilizing acoustic monitoring data, Carlson et al. (2008) found no correlation between movement rates and time-of-day for Atlantic sharpnose sharks. That adult Atlantic sharpnose and blacknose sharks are smaller bodied than the other 4 shark species examined could explain why there was no period of increased feeding intensity evident in our data. As energetic demand is reported to decrease with increasing body size (Schmidt-Nielsen 1984), small-bodied sharks could need to feed at a higher rate than larger congeners occupying the same habitat. As such, the sizerelated increase in energetic demand for small sharks could necessitate the relatively higher foraging activity indicated by our data. Therefore, it is possible that other factors, such as reproductive state, could significantly influence feeding rates of any species, regardless of size, due to increased energetic demands and thus make feeding chronology more dynamic than currently recognized.

While species-specific trends in times-of-capture were identified, the validity of our findings is contingent upon whether or not the presence of baited hooks motivates fishes to alter their natural behavior and feed during non-foraging periods. To our knowledge, no studies have examined the influence of baited hooks on chondrichthyan feeding motivation; however, Løkkeborg \& Bjordal (1989) investigated the effect of baited hook exposure on the feeding motivation of 2 teleost species. Using underwater television, the authors directly observed that when exposing cod Gadus morhua and haddock Melanogrammus aeglefinus to baited hooks throughout the diel cycle, a significantly lower percentage of individuals responded (e.g. ingestion or approach) during dark hours. This result led Løkkeborg \& Bjordal (1989) to conclude that differences in observed behaviors resulted from diel variation in feeding motivation. While we did not directly observe the behaviors of fishes in proximity to our sampling gear, time-of-capture data for great barracuda directly support the validity of our assumption in that great barracudas were not motivated to feed outside of their normal feeding times. Given this conclusion and the findings of Løkkeborg \& Bjordal (1989), we assert our data reflect the natural feeding patterns of the shark species we examined and believe our assumption is valid.

It has been stated that to properly estimate the feeding chronology of a given shark species one must employ stomach content analyses where individual meal times are reconstructed using qualitative stateof-digestion scales (Wetherbee \& Cortés 2004). While we agree that analyses of stomach contents provide valuable insight into the feeding chronology of sharks, we consider our methodology to be complimentary and, in some respects, more powerful. For example, our methodology is free from subjectivity as exists in the assignment of state of prey digestion, which is strongly influenced by a number of factors, including water temperature, meal size and prey type (Wetherbee \& Cortés 2004), all of which cannot be controlled or accounted for in a field setting. Additionally, studies utilizing stomach contents to examine the feeding chronology of large-bodied species almost exclusively focus on neonates and juveniles (e.g. Medved et al. 1985, Cortés \& Gruber 1990, Bush 2003, Barry et al. 2008, Kubodera et al. 2007, TorresRojas et al. 2010), with the notable exception of Barnett et al. (2010) who examined stomachs from all size classes of broadnose sevengill sharks Notorhynchus cepedianus. Conversely, our method includes all life stages that are susceptible to longline gear. This is particularly important as past studies have shown ontogenetic shifts to occur in the feeding biology of specific sharks (Wetherbee \& Cortés 2004), 
including Atlantic sharpnose (Hoffmayer \& Parsons 2003), blacktip (Barry et al. 2008), bull (Cliff \& Dudley 1991) and sandbar (McElroy et al. 2006) sharks. Furthermore, with the exception of Barnett et al. (2010) and aspects of Cortés \& Gruber (1990), all studies we are aware of that examined the feeding chronology of a shark species utilizing stomach content analyses used lethal methodology. While our method is logistically intensive, analyses of longline time-at-capture data does not require that individuals be sacrificed, thus making this methodology a non-lethal alternative to stomach content analyses.

Acknowledgements. We thank all of the participants of the National Marine Fisheries Service, Southeast Fisheries Science Center, Mississippi Laboratories bottom longline surveys, including M. Grace, K. Hannan, C. Jones, L. Jones, K. Mitchell and the crews of the NOAA Ships 'Oregon II', 'Gordon Gunter' and 'Ferrel' for their assistance in the collection of data. We also thank J. Castro and T. Henwood for their useful comments and suggestions.

\section{LITERATURE CITED}

Barnett A, Abrantes K, Stevens JD, Yick JL, Frusher SD, Semmens JM (2010) Predator-prey relationships and foraging ecology of a marine apex predator with a wide temperate distribution. Mar Ecol Prog Ser 416:189-200

Barry KP, Condry RE, Driggers WB III, Jones CM (2008) Feeding ecology and growth of neonate and juvenile blacktip sharks Carcharhinus limbatus in the TimbalierTerrebone Bay complex, LA, USA. J Fish Biol 73:650-662

$>$ Bres M (1993) The behaviour of sharks. Rev Fish Biol Fish 3: 133-159

> Bush A (2003) Diet and diel feeding periodicity of juvenile scalloped hammerhead sharks, Sphyrna lewini, in Kāne'ohe Bay, Ō'ahu, Hawai'i. Environ Biol Fishes 67:1-11

> Carlson JK, Heupel MR, Bethea DM, Hollensead LD (2008) Coastal habitat use and residency of juvenile Atlantic sharpnose sharks (Rhizoprionodon terraenovae). Estuaries Coasts 31:931-940

Cliff G, Dudley SFJ (1991) Sharks caught in the protective gill nets off Natal, South Africa. 4. The bull shark Carcharhinus leucas (Valenciennes). S Afr J Mar Sci 10: 253-270

Cortés E (1997) A critical review of methods of studying fish feeding based on analysis of stomach contents: application to elasmobranch fishes. Can J Fish Aquat Sci 54: 726-738

Cortés E (1999) Standardized diet composition and trophic levels of sharks. ICES J Mar Sci 56:707-717

Cortés E, Gruber SH (1990) Diet, feeding habits, and estimates of daily ration of young lemon sharks, Negaprion brevirostris (Poey). Copeia 1:204-218

Cortés E, Manire CA, Hueter RE (1996) Diet, feeding habits, and diel feeding chronology of the bonnethead shark, Sphyrna tiburo, in southwest Florida. Bull Mar Sci 58: 353-367

de Sylva DP (1963) Systematics and life history of the great barracuda Sphyraena barracuda (Walbaum). Stud Trop
Oceanogr, University of Miami Press, Coral Gables

Fisher NI (1993) Statistical analysis of circular data. Cambridge University Press, Cambridge

> Garla RC, Chapman DD, Wetherbee BM, Shivji M (2006) Movement patterns of young Caribbean reef sharks, Carcharhinus perezi, at Fernando de Noronha Archipelago, Brazil: the potential of marine protected areas for conservation of a nursery ground. Mar Biol 149:189-199

Gruber SH, Nelson DR, Morrissey JF (1988) Patterns of activity and space utilization of lemon sharks, Negaprion brevirostris, in a shallow Bahamian lagoon. Bull Mar Sci 43:61-76

Heithaus MR (2001) The biology of tiger sharks, Galeocerdo cuvier, in Shark Bay, Western Australia: sex ratio, size distribution, diet, and seasonal changes in catch rates. Environ Biol Fishes 61:25-36

Heithaus MR (2004) Predator-prey interactions. In: Carrier JC, Musick JA, Heithaus MR (eds) Biology of sharks and their relatives. CRC Press, Boca Raton, FL, p 487-521

Helfman GS (1986) Fish behaviour by day, night and twilight. In: Pitcher TJ (ed) The behaviour of teleost fishes. John Hopkins University Press, Baltimore, MD, p 366-387

Hoffmayer ER, Parsons GR (2003) Food habits of three shark species from the Mississippi Sound in the northern Gulf of Mexico. Southeast Nat 2:271-280

> Kubodera T, Watanabe H, Ichii T (2007) Feeding habits of the blue shark, Prionace glauca, and salmon shark, Lamna ditropis, in the transition region of the western North Pacific. Rev Fish Biol Fish 17:111-124

Løkkeborg S, Bjordal ^ (1989) Responses of cod (Gadus morhua) and haddock (Melanogrammus aeglefinus) to baited hooks in the natural environment. Can J Fish Aquat Sci 46:1478-1483

McElroy WD, Wetherbee BM, Mostello CS, Lowe CG (2006) Food habits and ontogenetic changes in the diet of the sandbar shark, Carcharhinus plumbeus, in Hawaii. Environ Biol Fishes 76:81-92

Medved RJ, Marshall JA (1981) Feeding behavior and biology of young sandbar sharks, Carcharhinus plumbeus (Pisces, Carcharhinidae), in Chincoteague Bay, Virginia. Fish Bull 79:441-447

Medved RJ, Marshall JA (1983) Short-term movements of young sandbar sharks, Carcharhinus plumbeus (Pisces: Carcharhinidae). Bull Mar Sci 33:87-93

Medved RJ, Stillwell CE, Casey JJ (1985) Stomach contents of young sandbar sharks, Carcharhinus plumbeus, in Chincoteague Bay, Virginia. Fish Bull 83:395-402

Randall JE (1967) Food habits of reef fishes of the West Indies. Stud Trop Oceanogr 5:665-847

Schmidt-Nielsen K (1984) Scaling: why is animal size so important? Cambridge University Press, New York, NY

Sciarrotta TC, Nelson DR (1977) Diel behavior of the blue shark, Prionace glauca, near Santa Catalina Island, California. Fish Bull 75:519-528

> Simpfendorfer CA (1998) Diet of the Australian sharpnose shark, Rhizoprionodon taylori, from northern Queensland. Mar Freshw Res 49:757-761

Springer S (1943) Sharks and their behavior with particular reference to eight genera implicated in reports of attacks on man. Report to the Coordinator of Research \& Development, USN Emergency Rescue Equipment Section

> Torres-Rojas YE, Hernández-Herrera A, Galván-Magaña F, Alatorre-Ramirez VG (2010) Stomach content analysis of juvenile, scalloped hammerhead shark Sphyrna lewini 
captured off the coast of Mazatlán, Mexico. Aquat Ecol 44:301-308

Tricas TC, Taylor LR, Naftel G (1981) Diel behavior of the tiger shark, Galeocerdo cuvier, at French Frigate Shoals, Hawaiian Islands. Copeia 4:904-908

Wetherbee BM, Cortés E (2004) Food consumption and feeding habits. In: Carrier JC, Musick JA, Heithaus MR (eds) Biology of sharks and their relatives. CRC Press, Boca Raton, FL, p 223-244

Wetherbee BM, Gruber SH, Cortes E (1990) Diet, feeding habits, digestion, and consumption in sharks, with spe-

Editorial responsibility: Nicholas Tolimieri, Seattle, Washington, USA cial reference to the lemon shark, Negaprion brevirostris. In: Pratt HL Jr, Gruber SH, Taniuchi T (eds) Elasmobranchs as a living resource: advances in the biology, ecology, systematics, and the status of the fisheries. NOAA Tech Rep 90:29-47

Whitney NM, Papastamatiou YP, Holland KN, Lowe CG (2007) Use of an acceleration data logger to measure diel activity patterns in captive whitetip reef sharks, Triaenodon obesus. Aquat Living Resour 20:299-305

Zar JH (1999) Biostatistical analysis, 4th edn. Prentice Hall, Upper Saddle River, NJ

Submitted: March 9, 2012; Accepted: June 26, 2012 Proofs received from author(s): September 14, 2012 